\title{
Review of Pastoralist Livelihoods in Asian Drylands: Environment, Governance and Risk edited by Ariell Ahearn and Troy Sternberg with Allison Hahn
}

\author{
Tracy Burnett(10
}

\author{
Book details: Ahearn, A, Sternberg, T with Hahn, A (eds.) \\ Pastoralist Livelihoods in Asian Drylands: Environment, Governance and Risk \\ Cambridgeshire: The White Horse Press, 2017 \\ Xiii +222 pages \\ ISBN 978-1-874267-98-0 (HB); 978-1-912186-07-5 (ebook)
}

Keywords: Pastoralism, Mongolia, Syria, Tibet, Oman, Kuchi, Rungs, Oran, India, Jordan

Pastoralist Livelihoods in Asian Drylands: Environment, Governance and Risk, published by The White Horse Press and edited by Ariell Ahearn and Troy Sternberg with Allison Hahn, is a collaborative book by scholars who have spent significant time with pastoral nomadic communities. The authors are familiar with a diverse array of pastoral societies and social theory; each case informs the other cases, and thus, through this book, the Asian drylands coalesce as a connected region with kindred pressures and, often, shared histories. ${ }^{1}$ It similarly becomes clear that many of these communities and scholars share an interest in actively constructing a future that accommodates the needs of Asian dryland environments and the communities inhabiting them. Together, these authors forward the claim that Asian dryland pastoralists are "resilient pastoralists, who are aware of and engaged in modernity and are making decisions about pastoralism and settlement from an informed and deliberate perspective" (p. 3) and that pastoralists can speak for themselves.

Each study herein describes a lived reality for a community that subsists with foraging livestock in an Asian dryland. Although the study sites range in place and

\footnotetext{
Correspondence: tracyburnett@berkeley.edu
}

Department of Environmental Science, Policy, and Management, University of California, Berkeley, 120 Mulford Hall MC 3110, Berkeley, CA 94720-3110, USA

scale from a village in Tibet to the country of Syria, each chapter is replete with trust that pastoralism is a viable lifestyle and a necessity in the twenty-first century. The authors' commitment to a future with pastoralist agency in society - including policy and economics - is evidenced by nuanced quotations from local herders, bibliographies that include references in regional languages, and optimism that pastoralists can and will persevere (especially if aided by government policies).

As such, this book is a statement that academic debate should engage Asian pastoral communities from the inside out - from their perspective - and expect them to flourish. It requires that pastoral communities be viewed neither as tools for driving environmental change nor as leaves caught in the winds of modern times but, rather, as agents with political and economic clout and their own agenda to pursue. Where pastoral communities have struggled in recent times, this book invites the reader to question any rising "sense [within themselves] that this lifestyle is unsustainable" and discern instead where perhaps "specific histories, policies, and programmes" created risk and insecurity for pastoralists (p. 10).

Three chapters in particular illustrate the impacts of specific policies on pastoralist livelihoods. First, Haian Dukhan's chapter ("From Reform to Revolt: Bashar Al-Assad and the Arab Tribes in Syria") contrasts the Syrian authoritarian state 
under Hafez al-Assad - who supported patronage networks that "allowed the state to become the major source of employment for the tribes" (p. 71) and who made credit, emergency fodder stocks, wells, rainwater retention enclosures, hospitals, and schools available to the tribes (p. 74) - with the regime of his son, Bashar, and the "disintegration of the social contract between the regime and the Arab tribes" (p. 71). Then, Gongbuzeren, in his chapter "Herder Participation in Modern Markets: the Issues of the Credit Loan Trap," found that "current market-based development systems promoted by the government narrowly focus on the development of markets and pay little attention to the response capacity of local herders, who are supposed to be the main beneficiaries; the ecological conditions affecting their livelihood; and the socio-cultural aspects of their livestock production system" (p. 105). Finally, Inam ur Rahim's chapter "Afghan/Pakistan Border Politics: What Future for Kuchi Nomads?" brings us up-to-date on the state of the Kuchi, many of whom annually cross the border between Afghanistan and Pakistan (the Durand line). The chapter remarks that "the Pakistani government... embarked on the construction of a physical barrier and completed a trench along the Baluchistan portion of the Durand line in 2016. Once the trench is completed along the entire border, crossing will only be possible at official crossing points, which will reduce the already limited livelihood options of the Kuchi" (p. 130-131). All three of these cases exemplify the destabilization of pastoral livelihoods by preventable external policies.

While some chapters certainly call for governments to better support the interwoven interests of pastoralists and Asian drylands, others provide eloquent explanations of why the current methods of scholarship and governance must be revised for the sake of both pastoralists and the land. Here, I draw attention to four pieces of this broader argument, each seated within a separate chapter.

1) First, the introduction makes it clear that much official and scholarly literature to date about pastoral communities has repeatedly asked, in endless debate, whether pastoralists live beyond state control, have their own formal governance structures, and/or live sustainable lifestyles (no, yes, and largely yes) (p. 6-10).

2) Then, in his chapter "The Afterlife of Nomadism: Pastoralism, Environmentalism, Civilisation and Identity in Mongolia and China," Bumochir Dulam draws our attention to how scholarly research can be exploited by statist forces, regardless of the original intent of the research: "[b]esides the actual content of Hardin and Ostrom's work, what matters is the way in which it is read and the argument applied in policies and related programmes." In other words, this chapter focuses not on "whether or not pastoralism [is] harmful to the environment"; the chapter instead maintains that by posing the academic question and answering it - even with answers as different as Garrett Hardin's and Elinor Ostrom's - the door opens for "different agencies, policy makers, activists, development practitioners and scholars [to]... popularise their [different] reading $[\mathrm{s}]$ of this literature." In Mongolia, this has often taken the form of creating "community based natural resource management" interventions that supersede extant management systems, be they formal or informal, sustainable, or not (p. 25-27).

3) Next, Salah al Mazrui, in his chapter "Indigenous Systems of Ecological Knowledge and Conservation Initiatives in Jabal Akhdar Mountain, Oman," points out that "[m]anagement of rangelands will hardly be successful if one is ignorant of how local communities perceive and give meanings to their tribal territories, where ancestors have been born and buried, wars have been fought, identities have been formed..." (p. 118). "Another important element to understand is how the territory is perceived and narrated by indigenous intellectuals or leaders, be they poets, writers, 'ulamä' (Islamic scholars) or tribal shaykhs. Landscape is not only about economics, politics or belonging, but also about aesthetics.... In this light, it is therefore also important to understand how landscape is portrayed through traditional arts such as poetry, music and literature, as all of these genres tend to evoke emotions and attachment to one's territory" (p. 118-119). Mazrui captured a transdisciplinary experience of the landscape in his article, and he also highlighted the irreducible role of indigenous intellectuals and endemic theorizations of landscape. This is indeed the next major source of theories that rangeland science must investigate, dialogue with, and incorporate.

4) Finally, in Aman Singh's chapter "From Stewards to Trespassers: Pastoralist Management of Forest Resources," he makes it clear that oran communal forests in Rajasthan, India, "are critically important pasture tracts for local livestock and meet the real needs of local people; productive orans result in less poverty and more livelihood security in communities." Singh details many of the innovative methods that villagers use to ensure the sustainability of oran natural resources in these scenarios. He also argues that interference with this dependent relationship (as oft-observed when states remove people from 
land for stated conservation purposes) begets "two consequences, one being the alienation of local people and the second being the deterioration of natural resources due to mismanagement" (p. 196). ${ }^{2}$ This chapter clearly illustrates the dual consequences of interfering with local, reciprocal dependencies between people and nature; it thereby offers strong evidence for rethinking current trends of development and environmental conservation.

Pastoralist Livelihoods in Asian Drylands inculcates an understanding of both why and how to heed the pastoral voice in academia and governance. It also takes a further step toward theorizing and implementing support for sustainable natural resource management by pastoralists. Byambabaatar Ichinkhorloo's chapter "Environment as Commodity and Shield: Reshaping Herders' Collective Identity in Mongolia" demonstrates that while Mongolian pastoralists' access to resources near and far is deeply embedded and cultivated in their social networks through a concept called nutag, herders have simultaneously now "revitalise[d] this collective identity in order to claim ownership over environmental resources" (p. 65). The consequence of communities claiming "ownership" in the private property sense is that "mobility for these same local people becomes restricted and pasture areas shrink as mechanisms of commodification deepen social and economic inequalities" (p. 64). In the scenario described by Ichinkhorloo, it is worth considering how pastoralists' social networks would instead guide resource management if the commoditization of the resources they subsist on were held at arm's length. Would this lend itself to greater social stability, environmental sustainability, and even livestock production ${ }^{3,4}$ in pastoral areas?

The context and question of social stability, environmental sustainability, and livestock production in pastoral areas are reminiscent of Karl Polanyi's description of the initial subjugation of land and social networks to market economics.

"Traditionally, land and labor are not separated; labor forms part of life, land remains part of nature, life and nature form an articulate whole. Land is thus tied up with the organizations of kinship, neighborhood, craft, and creed-with tribe and temple, village, guild, and church. One Big Market, on the other hand, is an arrangement of economic life which includes markets for the factors of production. Since these factors happen to be indistinguishable from the elements of human institutions, man and nature, it can be readily seen that market economy involves a society the institutions [man and nature] of which are subordinated to the requirements of the market mechanism" (Polanyi [1944] 2001, 187).

Ichinkhorloo's chapter bears witness to this subjugation process in Mongolian pastoral communities and highlights its restrictive consequences to land and pastoralist.

The diverse cultures and societies noted in this book share notable ecological constraints, namely, high spatial heterogeneity and temporal variability of natural resources. Each chapter studies a region differentially affected by external political, economic, and cultural pressures, but these two ecological constraints do not change. By playing political, economic, and cultural themes across such a vast area of scarce resources, we stir up the larger issue: can "commoditization of resources" itself be sustained in regions of such scarcity as these, or do these regions call the bluff of the inexorable spread of the market economy? And where market pressures undermine pastoralists' ability to subsist on their pastures, what do pastoralists themselves suggest as alternatives?

In addition to the chapters from Mongolia, Syria, Tibet in China, Oman, Afghanistan and Pakistan, and India mentioned in this review, Pastoralist Livelihoods in Asian Drylands contains a report on the Rungs of the Uttarakhand Himalayas, by Nisthasri Awasthi, and a study of the values inherent in Bedouin tent and contemporary house architecture in Jordan, by Wassef Al Sekhaneh. Many of the pastoral communities mentioned in these chapters face discrete, unprecedented political and economic obstacles, but this book also directs the reader's attention to the underlying trend - "which Chatty calls 'conservation without a human face"' (p. 10) - of development and environmental conservation models that sacrifice rural livelihoods and societies. Most notably, by couching its research firmly in the lived experience of pastoral communities, this book succeeds where others have failed in soldiering beyond common questions about pastoralists. Instead, it conducts crucial and timely research that assists pastoral communities unique, self-aware, and always adapting - with contributing to influential scholarly debates and flourishing in spite of modern obstacles.

Scholars who read this book will gain exposure to informed indigenous voices that advocate a redirection of scholarly attention. Practitioners working toward social stability and natural resource management in areas with pastoral constituents will be informed of useful concepts and case studies. For other readers, these case studies serve to normalize contemporary Asian pastoral cultures and their continuing relationships with national politics and the environment; therefore, I recommend this book to students or scholars of pastoralism or central, east, or south Asian studies and to people at large who take an interest in the rich future of pastoral societies. 


\section{Endnotes}

${ }^{1}$ Asian drylands, the book explains, include parts of East Asia as well as "the Arabian Desert, the Syrian Desert, Karakum, Kyzylkum and the Thar, located in the countries of Iraq, Iran, Jordan, Syria, Turkmenistan, Kazakhstan, Uzbekistan, India and Pakistan (Prăvălie 2016)” (p. 5).

${ }^{2}$ As an example, Singh describes: "[t]he oran of [Bhaktpura village] has been cut into two parts, one that is community controlled and another that has been enclosed as a forest reserve. The result of this has been that the reserved forest has been stripped bare-presumably by the local community-whereas the community controlled forests retain fairly thick stands of trees" (p. 186-187).

${ }^{3}$ Although not the focus of this book, livestock production is a hotly debated political and economic topic, and reported figures vary widely. There is evidence of highly sophisticated systems of pastoral livestock management that produce more benefits to society than alternative land uses. This is largely because "pastoralism traditionally makes highly intensive use of labour and social capital, in return for a great diversity of benefits, including multiple products and multiple environmental and cultural services. Transitioning from a highly labour-intensive mobile, multiple-value production system toward a sedentary, capital intensive single-output development model may appear to achieve resource efficiencies for that particular output (usually meat), but this narrows the range of products delivered by the system at the expense of overall social and environmental health" (McGahey et al. 2014, 20).

${ }^{4}$ Saverio Krätli's article "Cattle Breeding, Complexity and Mobility in a Structurally Unpredictable Environment: The WoDaaBe Herders of Niger" gives a thorough account of WoDaaBe pastoralists expending labour and social capital to maintain their herds of large Bororo cattle. "Instead of sheltering the animals from the rigour of the ecosystem and relying on external inputs to maximise peak production, the WoDaaBe engineer the animals' encounter with the ecosystem, through sophisticated knowledge/labour-intensive inputs, including a variety of instituted forms of mobility" (Krätli 2008, 30).

\section{Acknowledgements}

The author would like to thank Lynn Huntsinger for her helpful comments and review.

\section{Funding}

Not applicable

Availability of data and materials

Data sharing is not applicable to this article as no datasets were generated or analysed during the current study.

Authors' contributions

The author wrote, read and approved the final manuscript.
Authors' information

Not applicable

Competing interests

The author declares that she has no competing interests.

\section{Publisher's Note}

Springer Nature remains neutral with regard to jurisdictional claims in published maps and institutional affiliations.

Received: 6 March 2018 Accepted: 15 March 2018

Published online: 04 April 2018

\section{References}

Krätli, Saverio. 2008. Cattle breeding, complexity and mobility in a structurally unpredictable environment: The WoDaaBe herders of Niger. Nomadic Peoples 12 (1): 11-41.

McGahey, Daniel, Jonathan Davies, Nikolas Hagelberg, and Razingrim Ouedraogo. 2014. Pastoralism and the Green Economy - a natural nexus? Nairobi: IUCN and UNEP $x+58 p$

Polanyi, Karl. (1944) 2001. The great transformation: The political and economic origins of our time. Boston, MA: Beacon Press.

Prăvălie, Remus. 2016. Drylands extent and environmental issues. A global approach. Earth-Science Reviews 161: 259-278.

\section{Submit your manuscript to a SpringerOpen ${ }^{\circ}$ journal and benefit from:}

- Convenient online submission

Rigorous peer review

- Open access: articles freely available online

- High visibility within the field

- Retaining the copyright to your article

Submit your next manuscript at springeropen.com 